\title{
CAM Exercise Therapy
}

National Cancer Institute

\section{Source}

National Cancer Institute. CAM Exercise Therapy. NCI Thesaurus. Code C64896.

A form of treatment derived from Complimentary and Alternative Medicine (CAM) that uses various methods of movement in an effort to enhance physical, mental, and emotional health. 